\title{
Caracterização molecular do vírus da raiva isolado de Desmodus rotundus capturados no Estado do Rio de Janeiro
}

[Molecular characterization of rabies virus isolated from Desmodus rotundus captured in Rio de Janeiro State]

\author{
L.F.P. Vieira ${ }^{1}$, S.R.F.G. Pereira ${ }^{1}$, P.E. Brandão ${ }^{2}$, R.N. Oliveira $^{3}$, P. Carnieli-Junior ${ }^{3}$, \\ A.C. Galante ${ }^{1}$, C.N. Chicarino ${ }^{1}$, I. Kotait $^{3}$ \\ ${ }^{1}$ Centro de Ciências e Tecnologias Agropecuárias - HV-UENF \\ Av. Alberto Lamego, 2000 \\ 28013-602 - Campos dos Goytacazes, RJ \\ ${ }^{2}$ Faculdade de Medicina Veterinária e Zootecnia - USP - São Paulo, SP \\ ${ }^{3}$ Instituto Pasteur - São Paulo, SP
}

\begin{abstract}
RESUMO
Caracterizou-se filogeneticamente o vírus da raiva, isolado de morcegos hematógafos (Demodus rotundus). Cento e noventa e nove $D$. rotundus foram capturados em cinco abrigos, no Norte e Noroeste do Estado do Rio de Janeiro e sul do Espírito Santo. Sete deles foram positivos para a raiva. Amostras desses vírus foram sequenciadas e comparadas com sequências provenientes de diversos estados brasileiros. As sequências de vírus da raiva isoladas, na região norte do Estado do Rio de Janeiro, mostraram características que as distinguem de amostras de vírus isoladas em outras regiões do país, no entanto foram idênticas às isoladas de bovinos no noroeste do Rio de Janeiro.
\end{abstract}

Palavras-chave: vírus rábico, morcego hematófago, filogenética

\begin{abstract}
Rabies samples isolated from vampire bats captured in the Rio de Janeiro State were phylogenetically analyzed. One hundred and ninety nine vampire bats were captured from five shelters from North and Northwest of Rio de Janeiro and South of Espirito Santo States. Seven of them were positive for rabies. Theses samples were sequenced and compared with rabies virus sequences from several Brazilian states. The sequences of rabies virus, isolated in the present work, from North of Rio de Janeiro State, showed characteristics that differ of the sequences isolated from bats from other Brazilian regions. However, they were identical to samples isolated from cattle in Northwest of Rio de Janeiro state.
\end{abstract}

Keywords: rabies virus, vampire bat, phylogenetic

\section{INTRODUÇÃO}

$\mathrm{O}$ vírus da raiva pertence à família Rhabdoviridae e gênero Lyssavirus. Esse gênero é dividido em sete genótipos: Rabies virus (vírus clássico da raiva), Australian bat lyssavirus, Duvenhage virus, European bat lyssavirus I, European bat lyssavirus II, Lagos bat virus e Mokola vírus (ICTVdb, 2008).

A raiva é uma doença enzoótica nos países em desenvolvimento (World..., 2004). No Brasil, ainda ocorrem muitos casos de raiva humana, e o cão era o principal transmissor da raiva aos humanos, no entanto a campanha de vacinação iniciada na década de 80 diminuiu os casos da doença (Schneider et al., 1996). A incidência de raiva transmitida pelo morcego hematófago (Desmodus rotundus) aumentou, e desde 2004 este quiróptero tornou-se o principal transmissor da raiva aos humanos (Secretaria.., 2006).

Estima-se que 40 mil cabeças de gado morram pela raiva transmitida por $D$. rotundus no Brasil, causando prejuízo direto em torno de 15 milhões de dólares anuais (Kotait, 1998). No Estado do Rio de Janeiro, não acontece caso de raiva humana, embora a doença seja enzoótica em bovinos (Romijn et al., 2003).

Recebido em 22 de fevereiro de 2008

Aceito em 11 de fevereiro de 2010

E-mail: lfpv@uenf.br 
A caracterização genética e antigênica do vírus da raiva no Brasil segrega o vírus em, pelo menos, duas variantes: a variante do cão e a variante de $D$. rotundus. Essas variantes ainda podem ser filogeneticamente agrupadas por região geográfica de isolamento (Ito et al., 2003). Portanto, este trabalho propôs analisar, filogeneticamente, amostras isoladas de morcegos hematófagos, naturalmente infectados, capturados no Estado do Rio de Janeiro.

\section{MATERIAL E MÉTODOS}

Foram realizadas nove capturas de morcegos hematófagos em cinco abrigos localizados em cidades dos Estados do Rio de Janeiro e Espírito Santo, entre agosto de 2005 e setembro de 2006 (Tab. 1). Utilizando-se redes de neblina, armadas na saída de seus abrigos diurnos, foram capturados 199 morcegos. As capturas e a eutanásia foram autorizadas pelo Instituto Brasileiro do Meio
Ambiente e dos Recursos Naturais Renováveis e pelo Comitê de Ética da UENF.

O encéfalo dos morcegos foi colhido e estocado a $20^{\circ} \mathrm{C}$ até a análise, e o diagnóstico foi realizado pela técnica de imunofluorescência direta (Dean et al.,1996) e pelo isolamento viral em células de neuroblastoma murino (N2A) (Webster e Casey, 1996). As amostras de cérebro positivas na imunofluorescência e no isolamento viral foram submetidas à transcrição reversa - reação em cadeia pela polimerase (RT-PCR). O RNA total foi extraído com Trizol Reagent (Invitrogen), seguindo as recomendações do fabricante. A RT-PCR foi realizada como descrito por Orciari et al. (2001), com a substituição do primer $10 \mathrm{~g}$ pelo $21 \mathrm{~g}$. Os pares de primers utilizados nas duas reações foram o 21g (senso, ATGTAACACCTCTACAATG, posição 55-73 do genoma viral) e o 304 (antissenso, TTGACGAAGATCTTGCTCAT, posição 15141533 do genoma viral).

Tabela 1. Descrição das capturas de Desmodus rotundus realizadas nos Estados do Rio de Janeiro (RJ) e Espírito Santo (ES)

\begin{tabular}{|c|c|c|c|c|c|c|c|}
\hline \multicolumn{2}{|c|}{ Captura } & \multicolumn{2}{|c|}{ Local } & \multirow{2}{*}{$\begin{array}{l}\text { Tipo de } \\
\text { abrigo }\end{array}$} & \multicolumn{2}{|c|}{$\mathrm{N}$} & \multirow[b]{2}{*}{ Total } \\
\hline $\mathrm{N}^{\circ}$ & Data & Cidade/estado & $\begin{array}{l}\text { Posicionamento } \\
\text { geográfico }\end{array}$ & & Macho & Fêmea & \\
\hline 1 & $25 / 08 / 05$ & Italva/RJ & $\begin{array}{c}\text { S } 21^{\circ} 27^{\prime} 06,4^{\prime \prime} \\
\text { W } 041^{\circ} 43^{\prime} 34,2^{\prime \prime}\end{array}$ & Natural & 1 & 13 & 14 \\
\hline 2 & $20 / 10 / 05$ & $\begin{array}{l}\text { Bom Jesus do } \\
\text { Norte/ES }\end{array}$ & $\begin{array}{c}\text { S } 21^{\circ} 06^{\prime} 45,8^{\prime \prime} \\
\text { W } 041^{\circ} 40^{\prime} 55,6^{\prime \prime}\end{array}$ & Artificial & 13 & 18 & 31 \\
\hline 3 & $29 / 10 / 05$ & Miracema/RJ & $\begin{array}{c}\text { S } 21^{\circ} 23^{\prime} 39,3^{\prime \prime} \\
\text { W } 042^{\circ} 04^{\prime} 32,4^{\prime \prime}\end{array}$ & Natural & 26 & 21 & 47 \\
\hline 4 & $14 / 03 / 06$ & $\begin{array}{c}\text { Bom Jesus do } \\
\text { Norte / ES }\end{array}$ & $\begin{array}{c}\mathrm{S} 21^{\circ} 06^{\prime} 45,8^{\prime \prime} \\
\mathrm{W} 041^{\circ} 40^{\prime} 55,6^{\prime \prime}\end{array}$ & Artificial & 15 & 0 & 15 \\
\hline 5 & $16 / 03 / 06$ & $\begin{array}{c}\text { Campos dos } \\
\text { Goytacazes/RJ }\end{array}$ & $\begin{array}{c}\mathrm{S} 22^{\circ} 00^{\prime} 26,4^{\prime \prime} \\
\text { W } 041^{\circ} 40^{\prime} 00,3^{\prime \prime}\end{array}$ & Artificial & 4 & 0 & 4 \\
\hline 6 & 21/03/06 & Quissamã/RJ & $\begin{array}{c}\mathrm{S} 22^{\circ} 05^{\prime} 15,7^{\prime \prime} \\
\mathrm{W} 041^{\circ} 41^{\prime} 20,2^{\prime \prime}\end{array}$ & Artificial & 10 & 16 & 26 \\
\hline 7 & 26/07/06 & Quissamã/RJ & $\begin{array}{c}\mathrm{S} 22^{\circ} 05^{\prime} 15,7^{\prime \prime} \\
\mathrm{W} 041^{\circ} 41^{\prime} 20,2^{\prime \prime}\end{array}$ & Artificial & 46 & 7 & 53 \\
\hline 8 & $30 / 08 / 06$ & Quissamã / RJ & $\begin{array}{c}\text { S } 22^{\circ} 05^{\prime} 15,7^{\prime \prime} \\
\text { W } 041^{\circ} 41^{\prime} 20,2^{\prime \prime}\end{array}$ & Artificial & 3 & 0 & 3 \\
\hline 9 & 29/09/06 & $\begin{array}{l}\text { Bom Jesus do } \\
\text { Norte/ES }\end{array}$ & $\begin{array}{c}\text { S } 21^{\circ} 06^{\prime} 45,8^{\prime \prime} \\
\text { W } 041^{\circ} 40^{\prime} 55,6^{\prime \prime}\end{array}$ & Artificial & 5 & 1 & 6 \\
\hline Total & & & & & 123 & 76 & 199 \\
\hline
\end{tabular}

O produto da PCR foi purificado com o kit GFX (Amersham Biosciences) de acordo com as recomendações do fabricante. Em seguida, a reação de sequenciamento foi realizada com o kit BigDye Terminator v3.1 Cycle Sequencing (Applyed Biosystems) e purificado com o kit Sephadex (Amersham Biosciences). Por último, as sequências foram determinadas pelo sequenciador automático (ABI Prism 3100 - Applied Biosystems). Duas reações de sequenciamento foram realizadas para cada amostra, uma no sentido senso e outro no antissenso. Cada sequência foi revista no programa Cromas 2.24 (@1998-2004 Technelysium Pty Ltd), e a sequência completa foi obtida com o programa BioEdit 7.0.0 (@1997-2004 Tom Hall). As sequências produzidas nesse estudo foram publicadas no GenBank (Tab. 2). 
As sequências de nucleotídeos produzidas foram alinhadas com as obtidas no GenBank (Tab. 3), usando o programa ClustalW, presente no BioEdit 7.0.0, e o alinhamento resultou em sequências de 1360 nucleotídeos. A árvore filogenética foi gerada utilizando-se o método de distância com o algoritmo neighbor-joining e modelo evolutivo kimura-2-parâmetros, com 1.000 repetições de bootstrap, por meio do programa Mega2 (Kumar et al., 2001).
Tabela 2. Identificação das sequências de vírus da raiva, isoladas de $D$. rotundus e publicadas no

\begin{tabular}{ccc}
\multicolumn{2}{l}{ GenBank } & \\
\hline Captura & Amostra & N $^{\circ}$ de acesso GenBank \\
\hline \multirow{4}{*}{7} & 0399 & EF428576 \\
& $16-06$ & EF428577 \\
& $24-06$ & EF428578 \\
& $25-06$ & EF428579 \\
& $26-06$ & EF428580 \\
8 & $27-06$ & EF428581 \\
\hline
\end{tabular}

Tabela 3. Sequências obtidas no GenBank organizadas por número de acesso no GenBank, local de isolamento (cidade e estado), espécie de isolamento e ano de isolamento do vírus

\begin{tabular}{|c|c|c|c|c|}
\hline GenBank & Cidade & Estado & Espécie de Isolamento & Ano \\
\hline M13215 & - & - & - & - \\
\hline D42112 & - & - & - & - \\
\hline AB083793 & Goiânia & $\mathrm{GO}$ & Gato & 1999 \\
\hline AB083794 & Goiânia & $\mathrm{GO}$ & Gato & 1999 \\
\hline AB083795 & Goiânia & GO & Humano & 1999 \\
\hline AB083796 & Poços de Caldas & MG & Cão & 1987 \\
\hline AB083797 & Poços de Caldas & MG & Cão & 1989 \\
\hline AB083798 & Anápolis & $\mathrm{GO}$ & Cão & 1999 \\
\hline AB083801 & Goiânia & $\mathrm{GO}$ & Humano & 1999 \\
\hline AB083804 & Iporá & $\mathrm{GO}$ & Equino & 1998 \\
\hline AB083805 & São Roque & SP & Bovino & 1994 \\
\hline AB083806 & Taubaté & SP & Desmodus rotundus & - \\
\hline AB083807 & Pindamonhangaba & SP & Desmodus rotundus & 1998 \\
\hline AB083808 & Apiaí & SP & Ovino & 1992 \\
\hline AB083809 & Nova Olinda & $\mathrm{TO}$ & Bovino & 1998 \\
\hline AB083810 & Araguanã & TO & Bovino & 1999 \\
\hline AB083811 & Colinas do Tocantins & TO & Bovino & 1999 \\
\hline AB083813 & Alto taquari & MT & Bovino & 1999 \\
\hline AB083814 & Cáceres & MT & Bovino & 1999 \\
\hline AB083817 & Pijurá & SP & Bovino & 1989 \\
\hline AB083818 & Corumbaíba & $\mathrm{GO}$ & Bovino & 1999 \\
\hline AB117969 & Itapira & SP & Artibeus lituratus & 1998 \\
\hline AB 117970 & São José do Rio Preto & SP & Artibeus lituratus & 1998 \\
\hline AB117971 & Novo Horizonte & SP & Artibeus lituratus & 1998 \\
\hline AB 117972 & São José do Rio Preto & SP & Artibeus planirostris & 1998 \\
\hline AB201802 & Dracena & SP & Artibeus. lituratus & 2002 \\
\hline AB201803 & Lindóia & SP & Desmodus rotundus & 2000 \\
\hline AB201804 & Lindóia & SP & Desmodus rotundus & 2000 \\
\hline AB201805 & São José do Barreiro & SP & Desmodus rotundus & 2001 \\
\hline AB201806 & São José do Rio Preto & SP & Nyctinomops laticaudatus & 1999 \\
\hline AB201807 & São José do Rio Preto & SP & Nyctinomops laticaudatus & 1999 \\
\hline AB201808 & Nova Granada & SP & Nyctinomops laticaudatus & 2001 \\
\hline AB201809 & Américo de Campos & SP & Eumops auripendulus & 1998 \\
\hline AB201811 & São José do Rio Preto & SP & Eptesicus furinalis & - \\
\hline AB201814 & Catanduva & SP & Eptesicus furinalis & 2002 \\
\hline AB201815 & Jales & SP & Molossus molossus & 1999 \\
\hline AB201816 & Ilha Solteira & SP & Molossus molossus & 2002 \\
\hline AB201818 & Itapira & SP & Molossus abrasus & 2000 \\
\hline DQ640242* & Miracema & RJ & Bovino & 2002 \\
\hline DQ640246* & Porciúncula & RJ & Bovino & 2003 \\
\hline DQ640247* & Porciúncula & RJ & Bovino & 2003 \\
\hline DQ640248* & Porciúncula & RJ & Bovino & 2003 \\
\hline DQ640249* & Porciúncula & RJ & Bovino & 2003 \\
\hline DQ640252* & Porciúncula & RJ & Bovino & 2003 \\
\hline DQ640254* & Porciúncula & RJ & Bovino & 2003 \\
\hline
\end{tabular}

*Amostras que não compuseram a árvore filogenética devido ao seu reduzido tamanho da sequência. 


\section{RESULTADOS}

Sete dos 199 morcegos capturados foram positivos para a raiva pela imunofluorescência e isolamento viral em cultivo celular. Seis dos morcegos positivos foram capturados na captura 7 (0399, 16-06, 25-06, 26-06 e 27-06), o outro morcego foi apanhado na captura 8 (31-06). Todos os positivos foram capturados no mesmo abrigo, mas com diferença de um mês entre as duas capturas.

O sequenciamento parcial do gene da nucleoproteína das sete amostras de vírus da raiva resultou em sequências de 1360 nucleotídeos, as quais alinharam com a sequência completa da cepa do vírus Pasteur (PV - M13215), do nucleotídeo 101 ao 1460. Todas as sete amostras foram idênticas, exceto pela 2406 que apresentou uma substituição de nucleotídeo $(\mathrm{G} \rightarrow \mathrm{A})$ na posição 1123 .

A árvore filogenética (Fig. 1) foi dividida em cinco clusters principais, todos com valor de bootstrap de $100 \%$. O cluster 1 compreendeu amostras relacionadas à raiva em $D$. rotundus; os clusters 2, 3 e 4 amostras relacionadas à raiva em morcegos insetívoros; e o cluster 5 relacionadas à raiva canina. Em uma análise detalhada do cluster 1, pode-se perceber a formação de seis subclusters.

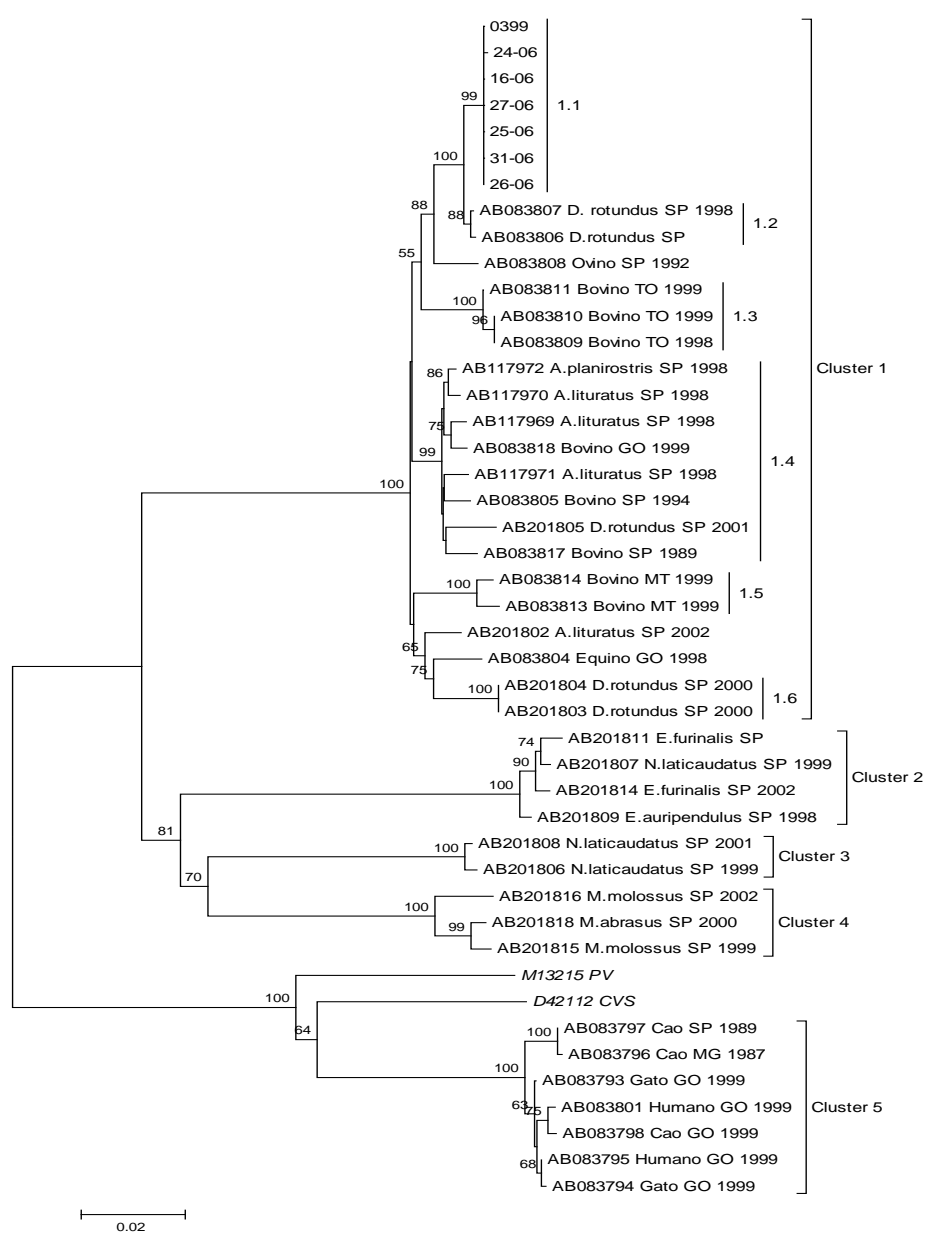

Figura 1. Árvore filogenética de distância para uma região de 1360 nucleotídeos do gene $\mathrm{N}$ do vírus da raiva. Amostras isoladas nesse trabalho estão no subcluster 1.1, amostras obtidas no GenBank estão identificadas pelo número de acesso, seguido da espécie de isolamento, estado e ano. Os valores de bootstrap acima de 50\% são mostrados acima dos nós e a escala representa o número de substituição de nucleotídeos pelo número total no alinhamento. 


\section{DISCUSSÃO}

Para a construção da árvore filogenética, além das sequências isoladas nesse estudo, foram utilizadas sequências de vírus da raiva provenientes de cães, animais de produção e morcegos frugívoros, insetívoros e hematófagos. Dentre as amostras isoladas de morcegos e animais de produção, as quais fazem parte do ciclo da raiva rural, foram selecionadas sequências dos Estados de Goiás, Mato Grosso, São Paulo e Tocantins.

$\mathrm{Na}$ árvore filogenética (Fig. 1), foi possível observar a segregação entre amostras de cães e morcegos. Também foi observada a formação de subclusters entre as amostras de vírus relacionadas a $D$. rotundus, de acordo com a região geográfica de isolamento, confirmando os resultados de diversos autores (Ito et al., 2001; Ito et al., 2003; Romijn et al., 2003; Sato et al., 2006).

O cluster 1 foi subdividido em seis subclusters. O subcluster 1.1 agrupou as amostras isoladas no presente trabalho, todas provenientes de morcegos hematófagos capturados no município de Quissamã, norte do Rio de Janeiro. As sequências isoladas nos demais Estados mostraram-se diferentes das amostras do Rio de Janeiro, agrupando-se nos outros subclusters.

As amostras isoladas em Quissamã também foram comparadas com oito sequências de vírus da raiva (uma de Miracema e sete de Porciúncula), isoladas de bovinos por Kimura (2006). As sequências alinhadas resultaram em fragmentos de 143 nucleotídeos. Devido ao seu reduzido tamanho, não entraram na árvore filogenética, contudo a matriz de identidade entre as amostras foi gerada. As amostras de Porciúncula mostraram $100 \%$ de identidade com as isoladas do presente trabalho em Quissamã, e a sequência de Miracema apresentou a substituição de um nucleotídeo, o que resultou em identidade de 99,3\%.

Em uma análise da raiva dos herbívoros no Estado do Rio de Janeiro, Romijin et al. (2003) observaram que amostras isoladas em uma mesma bacia hidrográfica tendem a formar clusters na árvore filogenética, indicando maior grau de identidade. No entanto, Quissamã está localizada em uma bacia hidrográfica diferente da de Porciúncula e Miracema. Talvez o foco da raiva tenha se deslocado de Miracema e Porciúncula até Quissamã. Segundo Tadei et al. (1991), no Estado de São Paulo, o foco da raiva move-se a uma velocidade de 16 a $21 \mathrm{~km}$ por mês, isto é, $200 \mathrm{~km}$ por ano. As distâncias entre Quissamã e Porciúncula e entre Quissamã e Miracema são de 90 e $130 \mathrm{~km}$, respectivamente, então a raiva chegaria a Quissamã antes de um ano, contudo o lapso de tempo entre os dois surtos foi de três anos.

Kobayashi et al. (2006), em análise da epidemiologia da raiva em D. rotundus, mostraram outro padrão de formação de clusters. As amostras de vírus da raiva, isoladas de regiões circundadas por grandes montanhas, são geneticamente mais próximas. Esse modelo é similar ao que foi encontrado entre as amostras de Quissamã, Porciúncula e Miracema, pois essas cidades ficam em uma faixa de altitude entre 0 e $200 \mathrm{~m}$.

Para estimar a confiança das análises com 143 nucleotídeos, as sequências utilizadas na árvore filogenética (Fig. 1) foram cortadas na porção 3' a fim de produzir fragmentos de 1350, 850, 650, 450, 250 e 140 nucleotídeos. Para cada tamanho foi construída uma árvore filogenética. Em todos os tamanhos de sequência, as árvores formaram os cinco clusters principais. As árvores construídas com os fragmentos de 1350 até 450 nucleotídeos formaram exatamente os mesmos clusters e subclusters. O subcluster 1.4 foi desorganizado na árvore construída com 250 nucleotídeos, e maiores alterações foram observadas na árvore de 140 nucleotídeos, sobretudo quanto à redução dos valores do bootstrap. Mesmo com o corte até 140 nucleotídeos, o subcluster 1.1, que agrupa as amostras isoladas no presente trabalho, foi mantido separado, com valor de bootstrap de $64 \%$.

Informações são perdidas com fragmentos menores, mas ainda podem ser utilizadas na construção da árvore filogenética, como também foi descrito por Kissi et al. (1995) e Ito et al. (2003). No entanto, alguns laboratórios amplificaram a porção inicial da nucleoproteína, e outros a porção final e, dessa forma, não é possível alinhar as sequências para análise. Portanto, é importante a amplificação do maior fragmento do gene, sempre que possível. 
Sugere-se existir, no Brasil, quatro variantes espécies-específica, isoladas de morcegos: uma de morcego hematófago $D$. rotundus e três de morcegos insetívoros Eptesicus furinalis, Molossus spp. e Nyctinomops laticaudatus (Kobayashi et al., 2005). Por outro lado, isolados virais de Artibeus spp., que são morcegos frugívoros, possuem alto grau de identidade de nucleotídeos com os vírus isolados de $D$. rotundus, o que sugere que pertencem ao mesmo ciclo epidemiológico (Shoji et al., 2004).

Nas capturas realizadas, foram encontrados, convivendo com $D$. rotundus, morcegos não hematófagos, principalmente o morcego frugívoro Carollia perscipilata. Portanto, para compor a árvore, foram selecionadas amostras de vírus isoladas de morcegos frugívoros e insetívoros, para se comparar com as de $D$. rotundus. As sequências produzidas no presente trabalho comportaram-se da mesma forma que a descrita pelos autores citados, ou seja, as sequências de vírus isoladas de $D$. rotundus e morcegos frugívoros (Artibeus spp.) agruparamse no mesmo cluster, enquanto as amostras de morcegos insetívoros formaram clusters separados.

\section{CONCLUSÃO}

O vírus da raiva, que circula no ciclo epidemiológico de D. rotundus no Estado do Rio de Janeiro, possui característica filogenética que o diferencia de isolados dos demais Estados brasileiros. O sequenciamento de amostras de todos os Estados brasileiros seria de grande auxílio para a vigilância epidemiológica da raiva no país.

\section{AGRADECIMENTOS}

Os autores agradecem à Fundação de Amparo à Pesquisa do Estado do Rio de Janeiro - FAPERJ, ao Instituto Pasteur de São Paulo, ao Centro de Controle de Zoonoses de Campos dos Goytacazes e ao Núcleo de Defesa Sanitária de Bom Jesus do Itabapoana.

\section{REFERÊNCIAS BIBLIOGRÁFICAS}

DEAN, D.J.; ABELSETH, M.K.; ATANASIU, P. The fluorescent antibody test. In: MESLIN, F.X.; KAPLAN, M.M.; KOPROWSKI, H. (Eds). Laboratory techniques in rabies. Genebra: World Health Organization, 1996. p.88-95.

ICTVdB - The Universal Virus Database, version $4 . \quad$ Disponível em <http://www.ncbi.nlm.nih.gov/ICTVdb/ICTVdB />. Acessado em: 18 jan. 2008.

ITO, M.; ARAI, Y.T.; ITOU, T. et al., Genetic characterization and geographic distribution of rabies virus isolates in Brazil: identification of two reservoirs, dogs and vampire bats. Virology, v.284, p.214-222, 2001.

ITO, M.; ITOU, T.; SHOJI, Y. et al. Discrimination between dog-related and vampire bat-related rabies viruses in Brazil by strainspecific reverse transcriptase-polymerase chain reaction and restriction fragment length polymorphism analysis. J. Clin. Virol., v.26, p.317-330, 2003.

KIMURA, L.M.S. Epidemiologia molecular de vírus da raiva em mamíferos domésticos e silvestres do Brasil. 2006. 80f. Tese (Doutorado) - Fundação Oswaldo Cruz, Rio de Janeiro, RJ.

KISSI, B.; TORDO, N.; BOURHY, H. Genetic polymorphism in the rabies virus nucleoprotein gene. Virology, v.209, p.526-537, 1995.

KOBAYASHI, Y.; OGAWA, A.; SATO, G. et al. Geographical distribution of vampire batrelated cattle rabies in Brazil. J. Vet. Med. Sci., v.68, p.1097-1100, 2006.

KOBAYASHI, Y.; SATO, G.; SHOJI, Y. et al. Molecular epidemiological analysis of bat rabies viruses in Brazil. J. Vet. Med. Sci., v.66, p.647652, 2005.

KOTAIT, I.; GONÇALVES, C.A.; PERES, N.F. Controle da raiva dos herbívoros. São Paulo: Instituto Pasteur,, 1998. 15p. (Manual técnico 1)

KUMAR, S.; TAMURA, K.; JAKOBSEN, I.B. et al. Mega2: molecular evolutionary analysis software. Bioinformatics, v.17, p.1244-1245, 2001. 
ORCIARI, L.A.; NIEZGODA, M.; HANLON, C.A. et al. Rapid clearance of SAG-2 rabies virus from dogs after oral vaccination. Vaccine, v.19, p.4511-4518, 2001.

ROMIJN, P.C.; HEIDE, R.V.D.; CATTANEO, C.A.M. et al. Study of lyssaviruses of bat origin as a source of rabies for other animal species in the state of Rio de Janeiro, Brazil. Am. J. Trop. Med. Hyg., v.69, p.81-86, 2003.

SATO, G.; KOBAYASHI, Y.; SHOJI, Y. et al. Molecular epidemiology of rabies from Maranhão and surrounding states in the northeastern region of Brazil. Arch. Virol., v.151, p.2243-2251, 2006.

SCHNEIDER, M.C.; ALMEIDA, G.A.; SOUZA, L.M. Controle da raiva no Brasil de 1980 a 1990. Rev. Saúde Públ.,v.30, p.193203, 1996.

SECRETARIA DE VIGILÂNCIA EM SAÚDE. Casos de Raiva Humana por Espécie Agressora, Brasil, 1986-2006. Disponível em: <http://www.saude.rj.gov.br/cvas/documentos/S \%E9rie\%20Hist\%F3rica\%20-

\%20Raivahumanaporagressora1986a2006.pdf>. Acessado em: 5 jan. 2006.
SHOJI, Y.; KOBAYASHI, Y.; SATO, G. ET al. Genetic characterization of rabies viruses isolated from frugivorous bat (Artibeus spp.) in Brazil. J. Vet. Med. Sci., v.66, p.1271-1273, 2004.

TADEI, V.A.; GONÇALVES, C.A.; PEDRO, W.A. ET al. Distribuição do morcego vampiro Desmodus rotundus (Chiroptera, Phyllostomidae) no estado de São Paulo e a raiva dos animais domésticos. Brasil, Campinas: CATI, 1991. 170p. (Impresso especial).

WEBSTER, W.A.; CASEY, G.A. Virus isolation in neuroblastoma cell culture. In: MESLIN, F.X.; KAPLAN, M.M.; KOPROWSKI, H. (Eds). Laboratory techniques in rabies. Genebra: World Health Organization, 1996. p.96-104.

WORLD HEALTH ORGANIZATION. WHO Expert Consultation on Rabies. Geneva: WHO, 2004. 121p. (First report). 